\title{
Conversion of Syringaldehyde to Sinapinic Acid through Knoevenagel-Doebner Condensation
}

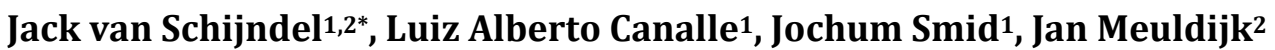

${ }^{1}$ Research Group Biopolymers, Centre of Expertise BioBased Economy, Avans University of Applied Science, Breda, The Netherlands ${ }^{2}$ Department of Chemical Engineering and Chemistry, Lab of Chemical Reactor Engineering/Polymer Reaction Engineering, Eindhoven University of Technology, Eindhoven, The Netherlands

Email: ${ }^{j}$ jam.vanschijndel@avans.nl

How to cite this paper: van Schijndel, J., Canalle, L.A., Smid, J. and Meuldijk, J. (2016) Conversion of Syringaldehyde to Sinapinic Acid through Knoevenagel-Doebner Condensation. Open Journal of Physical Chemistry, 6, 101-108.

http://dx.doi.org/10.4236/ojpc.2016.64010

Received: October 2, 2016

Accepted: October 24, 2016

Published: October 27, 2016

Copyright $\odot 2016$ by authors and Scientific Research Publishing Inc. This work is licensed under the Creative Commons Attribution International License (CC BY 4.0).

http://creativecommons.org/licenses/by/4.0/

\begin{abstract}
Sinapinic acid is a widespread compound in vegetable material and is as such common in the human diet. Recently it has drawn attention because of its biological activities. Sinapinic acid can be synthesized from syringaldehyde via the KnoevenagelDoebner condensation. However this reaction is limited by the formation of 4 -vinylsyringol after a second decarboxylation. To gain more detailed information about this reaction and to improve control over the formation of sinapinic acid, the concentration time history of syringaldehyde and the reaction products of this reaction have been monitored over time at different reaction temperatures. The formation of 4 -vinylsyringol was found to be inhibited by performing the reaction at temperature below $80^{\circ} \mathrm{C}$. This allows the reaction to be optimized for the production of sinapinic acid, with an optimal yield of $78 \%$ after 2.5 hours at $70^{\circ} \mathrm{C}$.
\end{abstract}

\section{Keywords}

Ligno-Phytochemicals, Sinapinic Acid, Knoevenagel-Doebner Condensation, 4-Vinylsyringol

\section{Introduction}

In the last decade, there has been increasing interest in the effective use of lignocellulosic materials. Research that focuses on the recovery and/or the synthesis of chemicals from biomass is a prerequisite to realize a sustainable chemical industry within a forward-looking bio-based economy. Large-scale processes are being developed that use all components in wood, i.e. cellulose, hemicellulose and lignin. In these multi-step multi-product bio-refinery facilities, lignin could serve as a bio-based source of 4-hydroxybenzaldehydes [1]. 
The Knoevenagel-Doebner reaction has always been an important and reliable method for the formation of carbon-carbon bonds and is frequently used in industry [2]. 4 -Hydroxybenzaldehydes can react with malonic acid in a Knoevenagel-Doebner reaction [3] to give the corresponding $\alpha, \beta$-unsaturated carboxylic acids known as hydroxycinnamic acids. In nature, hydroxycinnamic acids can be found in the plant kingdom as secondary metabolites. There are three common members of these so-called ligno-phytochemicals of which ferulic acid has been studied extensively, primarily due to its anti-oxidant properties [4]. Ferulic acid is therefore used as a natural preservative in foods, beverages, and cosmetics.

Aldabalde et al. [5] and Simpson et al. [6] proposed a mechanism for the KnoevenagelDoebner condensation of aromatic aldehydes and malonic acid using pyridine and piperidine as organocatalysts. The mechanism was illustrated by the conversion of vanillin into ferulic acid. During the reaction 2-methoxy-4-vinylphenol was observed as a second product following an extra decarboxylation step.

Sinapinic acid is another member of the hydroxycinnamic acid family [7]. Its effectiveness as anti-oxidant is considered to be superior over that of ferulic acid [8]. Moreover sinapinic acid shows anti-microbial, anti-inflammatory, anti-cancer and anti-anxiety activities. In this study, the transformation of syringaldehyde (1) to sinapinic acid (2) with the Knoevenagel-Doebner reaction was performed in more detail. The formation of the corresponding vinylphenol, 4-vinylsyringol (3) can be confirmed, but this formation reaction is temperature dependent.

\section{Materials and Methods}

\subsection{Materials}

The reactant syringaldehyde (1), and all other chemicals were purchased at $99 \%$ purity from Sigma-Aldrich and were used as received without further purification. DMSO- $d_{6}$ was purchased from Cambridge Isotope with 99 atom\% D.

\subsection{Methods}

Instrumentation: ${ }^{1} \mathrm{H}-\mathrm{NMR}$ spectroscopy measurements were performed on an Agilent $400-\mathrm{MHz}$ NMR system in DMSO- $d_{6}$. Data was acquired using VnmrJ 3 software. Chemical shifts are reported in ppm relative to tetramethylsilane (TMS).

HPLC analysis was carried out using a Liquid Chromatographic system (Agilent 1100 series) equipped with a diode array detector (Agilent 1200 series) and an autosampler injector with a $20 \mu \mathrm{L}$ loop (Agilent 1100 serie G1316A). The system was equipped with a Luna $5 \mu \mathrm{m} \mathrm{C18} \mathrm{column}(250 \mathrm{~mm} \times 4.6 \mathrm{~mm})$ using acetic acid:water:methanol $(0.01: 50: 50, \mathrm{v} / \mathrm{v} / \mathrm{v})$ as a mobile phase. The flow rate was $1.0 \mathrm{~mL} / \mathrm{min}$ at a temperature of $20^{\circ} \mathrm{C}$. The Agilent Chem Station Software was used for data analysis. The quantitative determination of components in the reaction mixtures was carried out by the external standard method and based on peak areas.

LC-MS analysis was performed using a Liquid Chromatographic system (Agilent 1200 series $)$ equipped with a Luna $3 \mu \mathrm{m} \mathrm{C18} \mathrm{column}(250 \times 2.0 \mathrm{~mm})$ and an ion trap 
(Agilent 6300 series).

\subsection{Synthetic Procedure}

Protocol for Knoevenagel-Doebner condensation: Malonic acid (1.0 g, $10 \mathrm{mmol})$ was dissolved in pyridine $(3.0 \mathrm{~mL}, 37 \mathrm{mmol})$. Syringaldehyde $(1,0.90 \mathrm{~g}, 5 \mathrm{mmol})$ and piperidine $(0.20 \mathrm{~mL}, 2 \mathrm{mmol})$ were subsequently added. The reaction was heated to the desired temperature and $50.0 \mu \mathrm{L}$ samples were taken for reversed phase HPLC analysis. The samples were immediately diluted in $7.5 \mathrm{~mL}$ methanol, filtered and analysed using the method described above. The calculated percentage of peak area of the component of interest is in relation to the total area of peaks.

After 3 hours, the reaction was stopped and pyridine was removed in vacuo. The residue was dissolved in a small amount of a saturated aqueous $\mathrm{NaHCO}_{3}$-solution and acidified to a $\mathrm{pH}$ of 2 with $6 \mathrm{M} \mathrm{HCl}$. The resulting precipitate was separated by filtration and washed with water. After recrystallization with a solution of water-ethanol $(\mathrm{v} / \mathrm{v})(3: 1)$, the crystals were separated by filtration and dried in a nitrogen atmosphere. 4-Vinylsyringol, was purified with column chromatography with ethyl acetate as eluent.

\subsection{Products}

The structures of syringaldehyde (1), sinapinic acid (2) were confirmed by ${ }^{1} \mathrm{H}-\mathrm{NMR}$, mass spectral data and by comparison with authentic samples available commercially. The structure of 4-vinylsyringol (3) was elucidated with LC/MS and, after purification with column chromatography, with ${ }^{1} \mathrm{H}-\mathrm{NMR}$ (see representative examples in Supporting Information).

(E)-3-(4-hydroxy-3,5-dimethoxyphenyl)-2-propenoic acid (sinapinic acid, 2) $\left(\mathrm{C}_{11} \mathrm{H}_{12} \mathrm{O}_{5}\right.$, $\mathrm{M}=224.21 \mathrm{~g} / \mathrm{mol})$ isolated as a white powder.

${ }^{1} \mathrm{H}-\mathrm{NMR}(400 \mathrm{MHz}, \mathrm{DMSO}) \delta(\mathrm{ppm}) 12.10(\mathrm{~s}, 1 \mathrm{H}), 8.87$ (s, 1H), 7.47 (d, 1H), 6.96 (s, $2 \mathrm{H}), 6.39(\mathrm{~d}, 1 \mathrm{H}), 3.78(\mathrm{~s}, 6 \mathrm{H})$. Mass spectrum recorded in negative ion mode, $[\mathrm{M}-\mathrm{H}]^{-}$ $\mathrm{m} / \mathrm{z} 222.8$.

2,5-dimethoxy-4-vinylphenol (4-vinylsyringol, 3) $\left(\mathrm{C}_{10} \mathrm{H}_{12} \mathrm{O}_{3}, \mathrm{M}=180.20 \mathrm{~g} / \mathrm{mol}\right.$ ) isolated as a brown liquid.

${ }^{1} \mathrm{H}-\mathrm{NMR}(400 \mathrm{MHz}, \mathrm{DMSO}) \delta(\mathrm{ppm}) 6.72(\mathrm{~s}, 2 \mathrm{H}), 6.63(\mathrm{~d}, 1 \mathrm{H}), 5.61(\mathrm{dd}, 1 \mathrm{H}), 5.35$ $(\mathrm{s}, 1 \mathrm{H}), 5.18(\mathrm{dd}, 1 \mathrm{H}), 3.85(\mathrm{~s}, 6 \mathrm{H})$. Mass spectrum recorded in negative ion mode, $[\mathrm{M}-\mathrm{H}]^{-} \mathrm{m} / \mathrm{z} 178.8$.

\section{Results and Discussion}

Aldabalde et al. [6] previously reported the conversion of vanillin to ferulic acid using the Knoevenagel-Doebner condensation. In their study, the reaction was performed in refluxing pyridine $\left(115^{\circ} \mathrm{C}\right)$ which served as solvent. Piperidine served as organocatalyst in both the carbon-carbon bond formation and the consecutive decarboxylations. The use of organocatalysts in organic synthesis is environmentally beneficial as stated by the Green Chemistry principles [9]. Under these conditions 2-methoxy-4-vinylphenol is the major product. For the Knoevenagel-Doebner condensation of syringaldehyde (1) 
and malonic acid towards sinapinic acid (2), we therefore decreased the temperature in the range of $50^{\circ} \mathrm{C}$ to $90^{\circ} \mathrm{C}$ to suppress the second decarboxylation which results in the vinylphenolic product (3) (Figure 1). We moreover used smaller amounts of the organocatalyst piperidine to further limit the environmental impact ( 0.2 eq instead of $0.4 \mathrm{eq}$ used in the procedure of Aldabalde et al.).

From the results obtained, it is evident that the conversion rate of syringaldehyde is increased with temperature (Figure 2(a)). This is also the case with the formation of

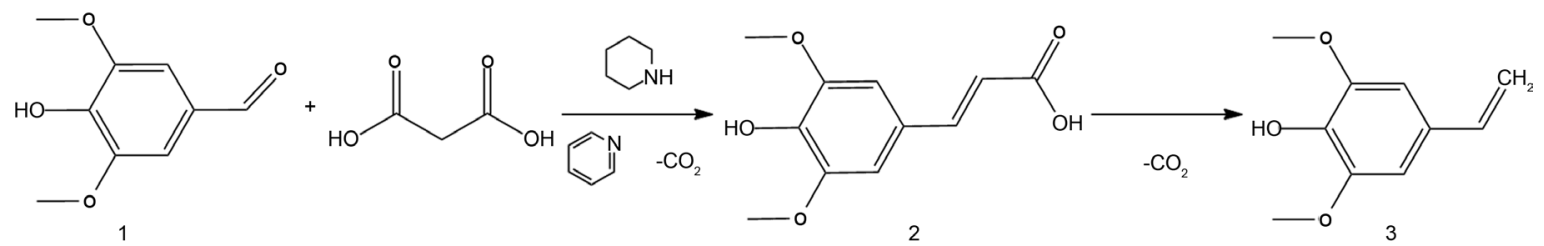

Figure 1. Knoevenagel-Doebner condensation of syringaldehyde (1) with malonic acid toward sinapinic acid (2), followed by a second decarboxylation leading to 4-vinylsyringol (3).

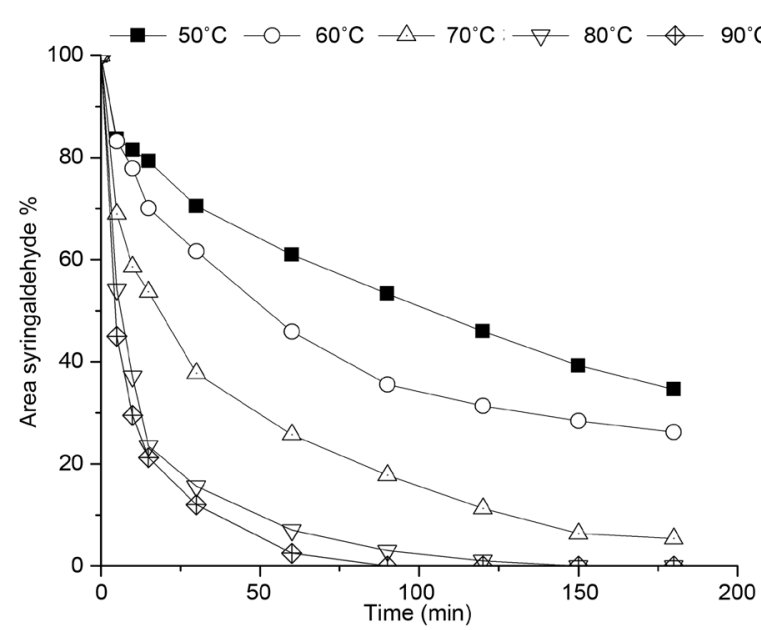

(a)

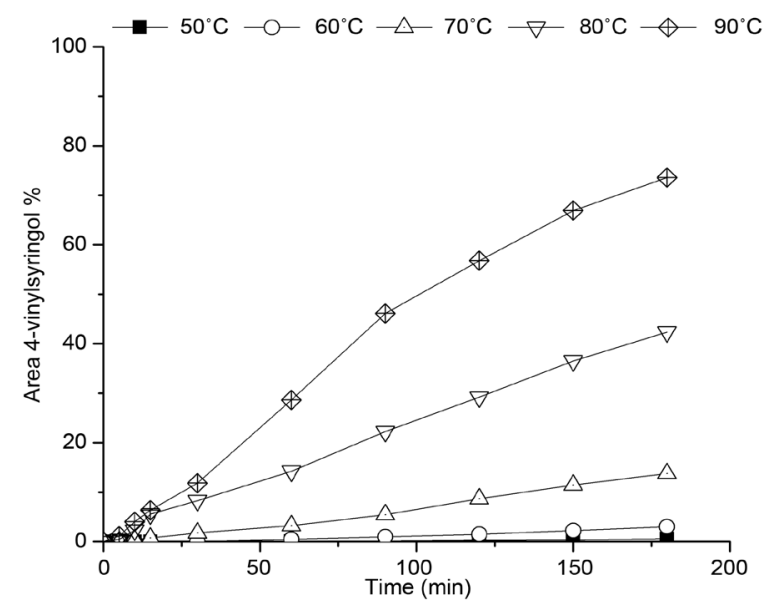

(c)

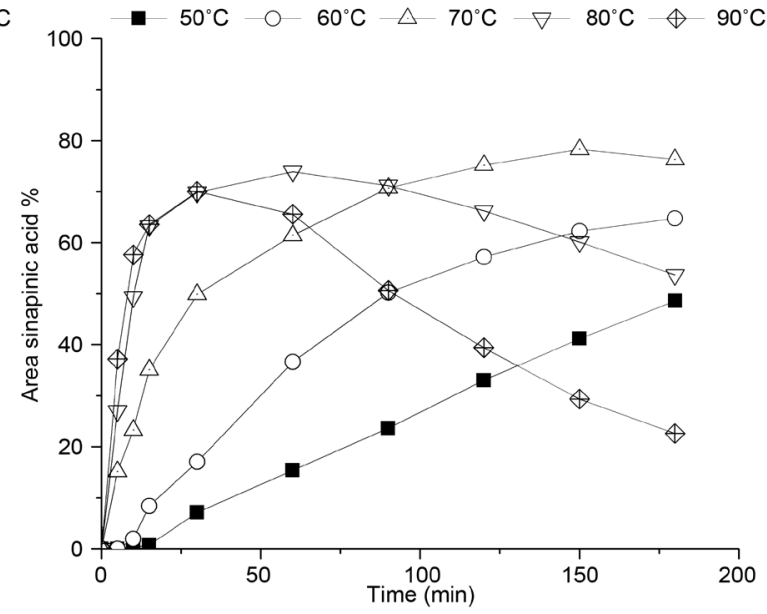

(b)

Figure 2. Concentration-time profiles of syringaldehyde (a), sinapinic acid (b) and 4-vinylsyringol (c) at various temperatures between $50^{\circ} \mathrm{C}$ and $90^{\circ} \mathrm{C}$. 
sinapinic acid (2), but there seems to be an optimum between $70^{\circ} \mathrm{C}$ and $80^{\circ} \mathrm{C}$ (Figure 2(b)).

At temperatures above $70^{\circ} \mathrm{C}$ the formation of 4-vinylsyringol (3) as a second product is observed (Figure 2(c)) following a second decarboxylation step. 4-Vinylsyringol and sinapinic acid can be separated by HPLC and their structures have been confirmed with ${ }^{1} \mathrm{H}$-NMR and mass spectrometry. Furthermore, it should be noted that the formation of 4-vinylsyringol complicates the isolation of sinapinic acid using precipitation. Pure sinapinic acid forms a free flowing powder, while a 4-vinylsyringol contamination changes the morphology of the product into an oily, sticky material. The optimal conversion for the production of sinapinic acid from syringaldehyde was $78 \%$ after 2.5 hours at $70^{\circ} \mathrm{C}$.

\section{Conclusion}

This study supports the mechanism for the Knoevenagel-Doebner condensation between syringaldehyde and malonic acid as proposed by Aldabalde et al. Additionally, the formation of the vinylphenolic product via a second decarboxylation step was found to be inhibited by performing the reaction at a temperature below $80^{\circ} \mathrm{C}$. This allows the Knoevenagel-Doebner reaction to be optimized for the production of sinapinic acid. The optimal conversion for sinapinic acid was $78 \%$ after 2.5 hours at $70^{\circ} \mathrm{C}$. In the present protocol pyridine is only used as a solvent. Because of pyridines environmental impact it would be worthwhile to diminish or eliminate its use and investigate alternatives.

\section{Acknowledgements}

Funding of this work came from SIA RAAK and of the Dutch National Science Foundation (NWO). We thank Edward Knaven, Avans University of Applied Science, for expert help with the LC/MS measurements and Bart Noordover, Eindhoven University of Technology, for his guidance and advice.

\section{References}

[1] Fitzpatrick, M., Champagne, P., Cunningham, M.F. and Whitney, R.A. (2010) Bioresource Technology A Biorefinery Processing Perspective: Treatment of Lignocellulosic Materials for the Production of Value-Added Products. Bioresource Technology, 101, 8915-8922. http://dx.doi.org/10.1016/j.biortech.2010.06.125

[2] Knoevenagel, E. (1894) Ueber eine Darstellungsweise der Glutarsäure. Chemische Berichte, 27, 2345-2346. http://dx.doi.org/10.1002/cber.189402702229

[3] List, B. (2010) Emil Knoevenagel and the Roots of Aminocatalysis. Angewandte Chemie International Edition, 49, 1730-1734. http://dx.doi.org/10.1002/anie.200906900

[4] Ou, S. and Kwok, K. (2004) Ferulic Acid: Pharmaceutical Functions, Preparation and Applications in Foods. Journal of the Science of Food and Agriculture, 84, 1261-1269. http://dx.doi.org/10.1002/jsfa.1873

[5] Aldabalde, V., Risso, M., Derrudi, M.L., Geymonat, F., Seoane, G., Gamenara, D. and Saenz-Méndez, P. (2011) Organocatalyzed Decarboxylation of Naturally Occurring Cinnamic Acids: Potential Role in Flavoring Chemicals Production. Open Journal of Physical 
Chemistry, 1, 85-93. http://dx.doi.org/10.4236/ojpc.2011.13012

[6] Simpson, C.J., Fitzhenry, J. and Stamford, N.P.J. (2005) Preparation of Vinylphenols from 2- and 4-Hydroxybenzaldehydes. Tetrahedron Letters, 46, 6893-6896. http://dx.doi.org/10.1016/j.tetlet.2005.08.011

[7] Nićiforović, N. and Abramovič, H. (2014) Sinapic Acid and Its Derivatives: Natural Sources and Bioactivity. Comprehensive Reviews in Food Science and Food Safety, 13, 34-51. http://dx.doi.org/10.1111/1541-4337.12041

[8] Cuvelier, M., Berset, C. and Richard, H. (1992) Comparison of the Antioxidative Activity of Some Acid-Phenols: Structure-Activity Relationship. Bioscience, Biotechnology, and Biochemistry, 56, 324-325. http://dx.doi.org/10.1271/bbb.56.324

[9] Sheldon, R.A. (2012) Fundamentals of Green Chemistry: Efficiency in Reaction Design. Chemical Society Reviews, 41, 1437-1451. http://dx.doi.org/10.1039/C1CS15219J 


\section{Supporting Information}

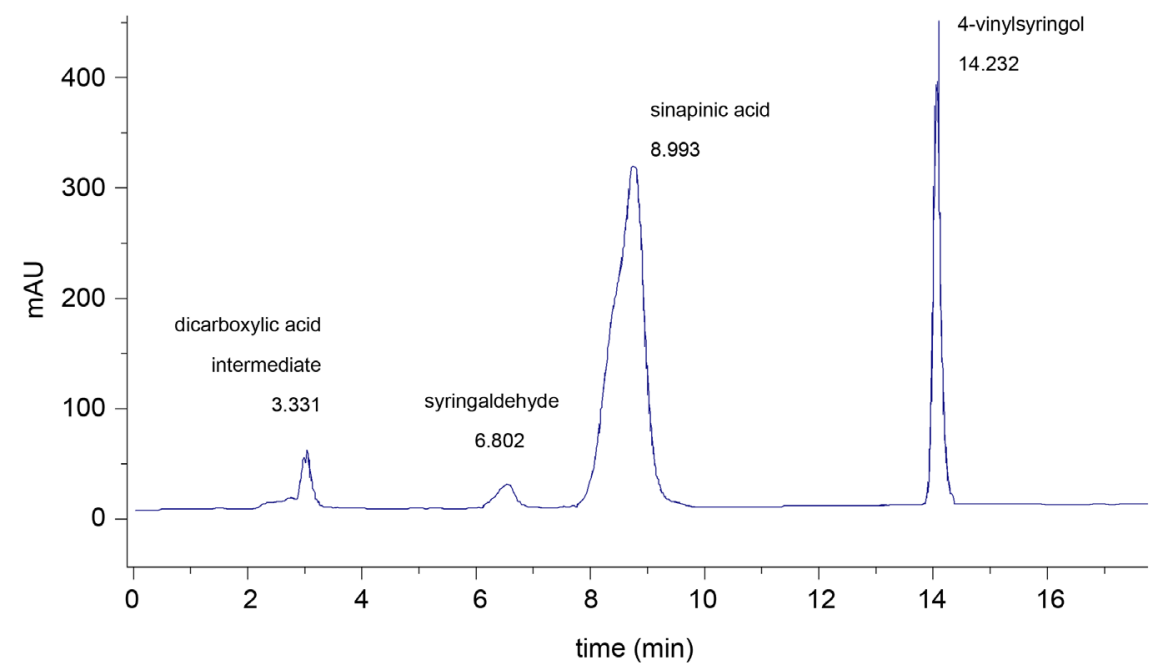

Figure S1. Example of HPLC chromatogram where both sinapinic acid and 4-vinylsyringol are separated. Area percentages were obtained from comparative integration of peaks. e.g. dicarboxylic acid intermediate $3.9 \%$, syringaldehyde $3.1 \%$, sinapinic acid $69.3 \%$ and 4 -vinylsyringol $21.5 \%$.

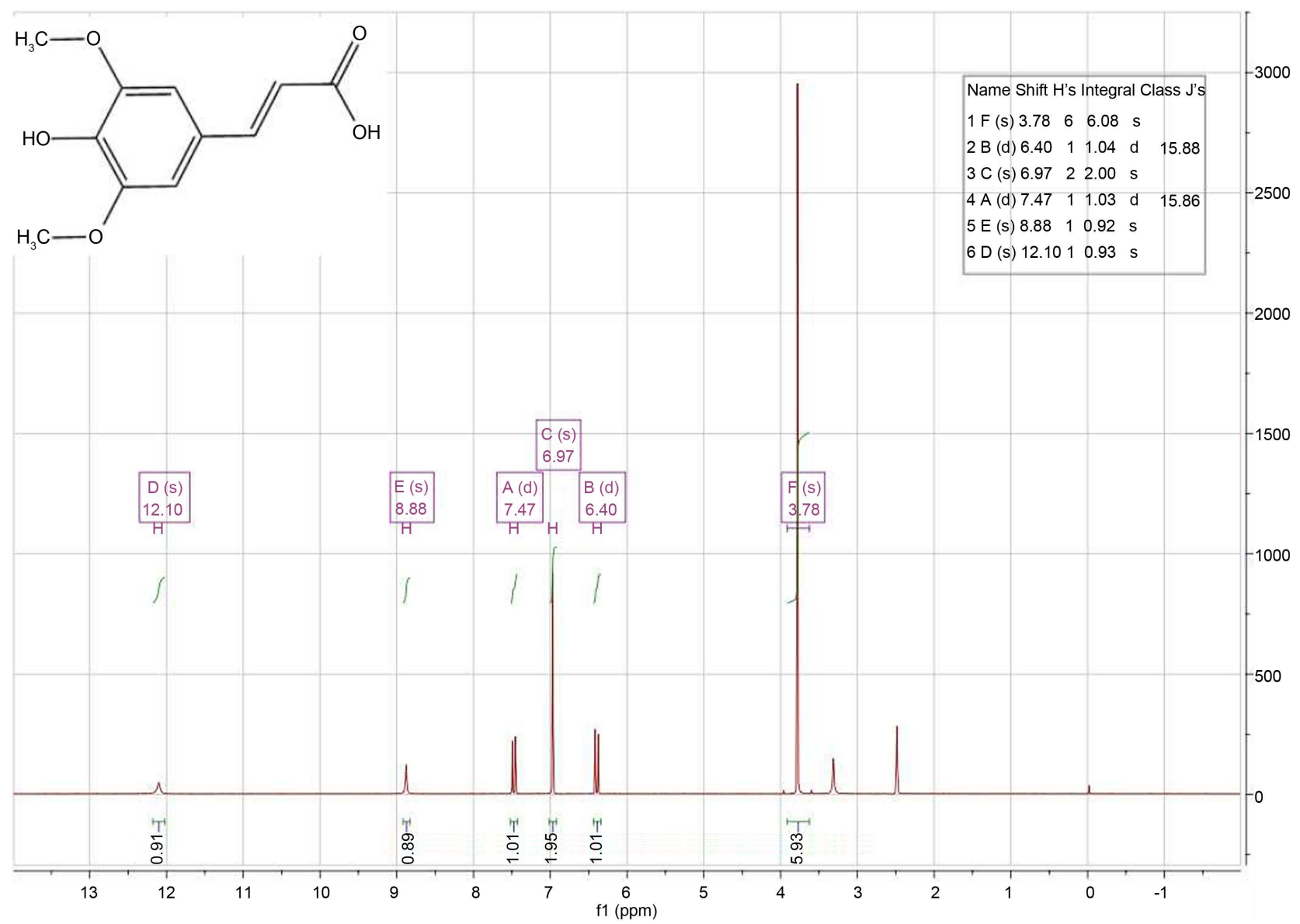

Figure S2. ${ }^{1} \mathrm{H}-\mathrm{NMR}$ (DMSO- $\left.d 6\right)$ of isolated sinapinic acid. ${ }^{1} \mathrm{H}$ NMR (400 MHz, DMSO) $\delta 12.10(\mathrm{~s}, 1 \mathrm{H}), 8.88(\mathrm{~s}, 1 \mathrm{H}), 7.47(\mathrm{~d}, \mathrm{~J}=$ $15.9 \mathrm{~Hz}, 1 \mathrm{H}), 6.97$ (s, 2H), 6.40 (d, J = $15.9 \mathrm{~Hz}, 1 \mathrm{H}), 3.78(\mathrm{~s}, 6 \mathrm{H})$. 

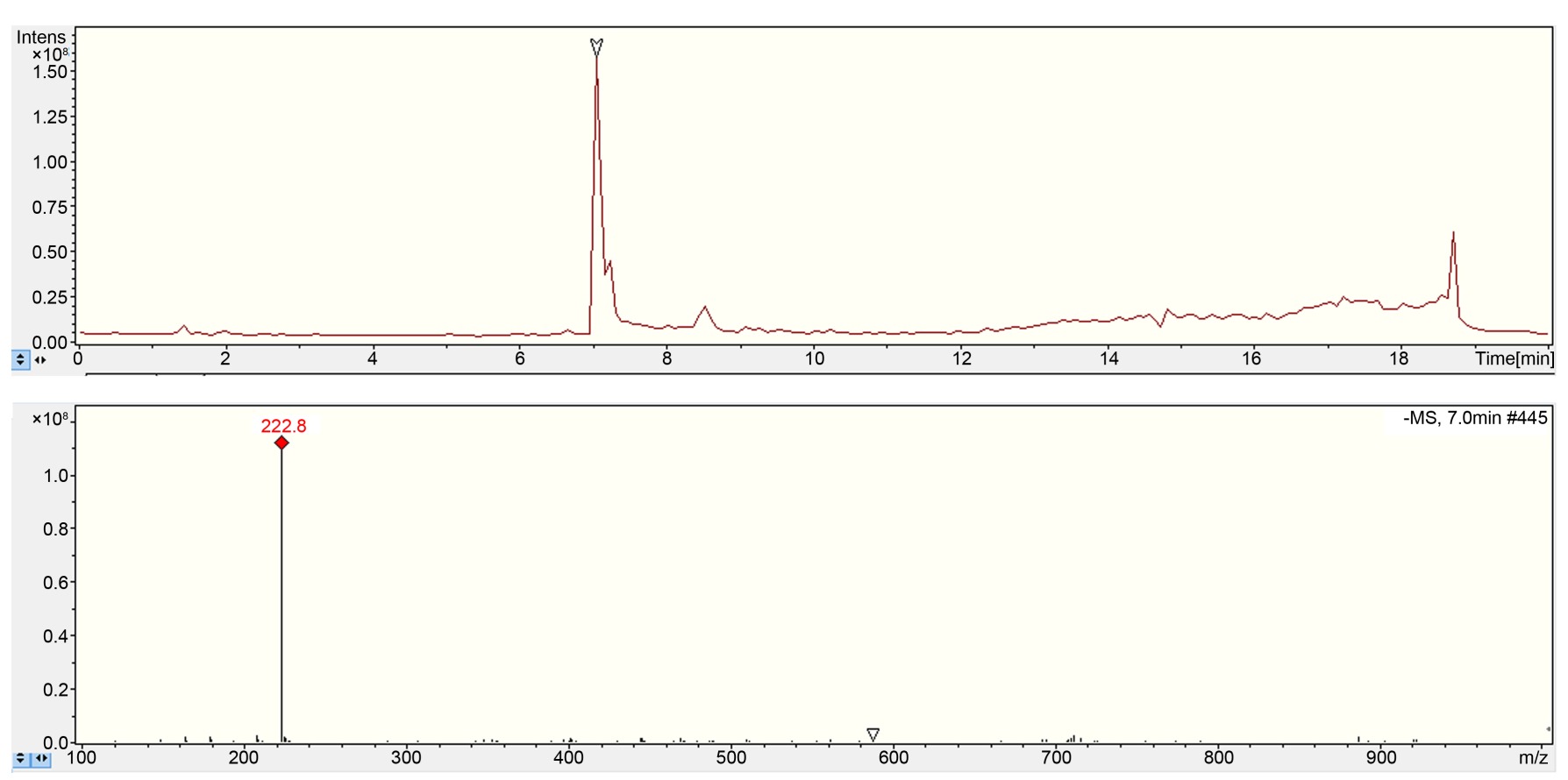

Figure S3. Mass spectra in negative ion mode identified peak as sinapinic acid $(\mathrm{M}=224.21 \mathrm{~g} / \mathrm{mol})$ by the molecular ion $[\mathrm{M}-\mathrm{H}]^{-} \mathrm{m} / \mathrm{Z}$ 222.8 .

Submit or recommend next manuscript to SCIRP and we will provide best service for you:

Accepting pre-submission inquiries through Email, Facebook, LinkedIn, Twitter, etc. A wide selection of journals (inclusive of 9 subjects, more than 200 journals)

Providing 24-hour high-quality service

User-friendly online submission system

Fair and swift peer-review system

Efficient typesetting and proofreading procedure

Display of the result of downloads and visits, as well as the number of cited articles

Maximum dissemination of your research work

Submit your manuscript at: http://papersubmission.scirp.org/

Or contact ojpc@scirp.org 